\title{
Regressed retinopathy of prematurity and its sequelae in children aged 5-10 years
}

\author{
Juan E Gallo, Gerd Holmström, Ulla Kugelberg, Bo Hedquist, Gunnar Lennerstrand
}

\begin{abstract}
Regressed retinopathy of prematurity (ROP) and its sequelae were studied in children born prematurely ( $<1501 \mathrm{~g}$ birth weight and/or $<33$ weeks gestational age) in Stockholm county during 1976-81. Through various searches of the records at the different eye departments and other sources in Stockholm county we found that 134 out of a total of 528 premature babies $(25.4 \%)$ had needed ophthalmic care for different reasons. They were re-examined and reliable information on the fundus could be obtained for 105 of them. The frequency of regressed ROP was $45 \cdot 5 \%$. Severe forms with vitreoretinal scarring and retinal traction were seen in $9.7 \%$ of cases and moderate forms with pigmentary changes and/or vitreoretinal interphase changes in $35.8 \%$. The sequelae of regressed ROP were mainly reduction of visual acuity and myopia. Children with a birth weight below $1000 \mathrm{~g}$ and a gestational age $<30$ weeks presented the highest rate of regressed ROP $(68.5 \%$ and $61.9 \%)$ and ocular abnormalities.
\end{abstract}

Retinopathy of prematurity (ROP) is known as a potentially blinding disease. Phelps has estimated that $8 \%$ of infants with a birth weight of $1000 \mathrm{~g}$ or less become blind from ROP in the United States. ${ }^{1}$ In addition a broad spectrum of ocular abnormalities have been reported as complications of ROP. ${ }^{2-5}$

In the last decade important work has been done to prevent and diminish the severity of ROP..$^{6-8}$ We have conducted a retrospective study in prematurely born children in Stockholm county during 1976-81 in order to investigate the occurrence of ocular abnormalities. This paper deals with regressed ROP and its sequelae. A comparative study on the prevalence of visual impairments, refractive errors, and ocular motility disorders in premature babies and a control group of full-term babies will be reported separately. Some of the results have been published in a preliminary form.'

\section{Material and methods}

\section{EPIDEMIOLOGICAL CONSIDERATIONS}

To be able to evaluate retrospective epidemiological studies of this kind some information on the Swedish health care system is needed. All births in Sweden are reported to the Board of Health and Welfare. Among other things the birth weight and the gestational age of the child is recorded together with information on the date of birth, the sex, etc. The accuracy of the registration has been tested (report 1977-02-10 of the Board of Health and Welfare). Errors in date of birth were found in $0.3 \%$, in sex in $0.3 \%$, and in weight in $1.0 \%$ of the reports. These numbers refer to the same period of time as our study.

The use of the 10-digit person identification number in different Swedish registers makes it fairly easy to obtain information on the patients within the health care system, and also to keep track of visits that the patients make to different hospitals and private offices.

During the period of our investigation, all prematurely born children in Stockholm county were cared for at five different neonatal units. The treatment schemes of the departments have been very similar, at least for the same period of time, and also quite advanced from an international standpoint.

Paediatric ophthalmology services are mainly provided at three departments in Stockholm county. All children below the age of 5 are referred to these centres with very few exceptions. The somewhat older children were sometimes referred to a limited number of ophthalmologists outside these centres. With this knowledge of the system for paediatric ophthalmic care it was fairly easy to obtain complete coverage of information on the groups of children that we were interested in.

During the period 1976-81 prematurely born children were not examined regularly by ophthalmologists in the neonatal wards, and there were no particular arrangements for ophthalmological follow-up of these children. However, they were included in the general health care system for children, which implies that the child was examined regularly at the health care centres for children and referred for ophthalmic investigation when needed. All children were screened for reduced visual acuity in each eye at the age of 3.5-4 years, and those who fell below the accepted limits were referred for ophthalmic examination. The rate of participation in these screening procedures is very high, about $95-98 \%$ of the population. ${ }^{10}$ At visual acuity testing during first grade in school very few new cases of visual impairment are discovered when the screening at 3.5-4 years is done correctly. ${ }^{11}{ }^{12}$ Most of the early ocular problems of children should therefore have been discovered and cared for by the age of 5 years.

\section{POPULATION OF PREMATURE INFANTS}

From the birth registers of the Swedish National Board of Health and Welfare all preterm children born in Stockholm county from 1 January 1976 to 31 December 1981 (a six-year period) were selected for the study if they had a birth weight $<1501 \mathrm{~g}$ and/or a gestational age $<33$ weeks. Gestational age was determined according to the method of Dubowitz et al. ${ }^{13}$ Our criteria for 
prematurity in this study included birth weight and/or gestational age, since we wanted to reduce the number of children that had been reported with an incorrect value in any of the parameters. In recent studies the most common criterion has been birth weight below $1500 \mathrm{~g}$ alone. However, the mean birth weight of Swedish prematures at 32 weeks gestation is $1750 \mathrm{~g}$. The limit $1500 \mathrm{~g}$ would have eliminated many quite premature children in our material. Nonetheless, prematures with a birth weight $\geqslant 2000 \mathrm{~g}$ were excluded from the study.

The population of prematures consisted of 528 children, not counting those who had died or moved from the area. The distribution with regard to birth weight and other details of the premature population is shown in Table 1 .

By means of listings of the 10-digit person identification numbers of the premature children manual searches were made at the archives of ophthalmology departments and other sources in Stockholm county as well as over the Stockholm county computer system. A total of 134 prematures had been seen by ophthalmologists and orthoptists for various reasons (Table 1). The charts of these children were obtained from the departments, and they were analysed with regard to the ophthalmological parameters listed below. The study was approved by the Ethical Committee of the Karolinska Institute, Stockholm, Sweden.

\section{OPHTHALMIC EXAMINATION}

Every child underwent a standard examination of visual function and ocular motility. If the patient had been examined repeatedly, data from the last report was used in this study.

Visual acuity and refractive errors. Visual acuity was determined with Snellen charts adjusted to the age of the child. Blindness was defined as a visual acuity of less than $0.03(2 / 36)$ in the better eye. Refraction was done with cycloplegia. A measure of static refraction was taken as that with which the patient achieved the best visual acuity. Spherical equivalents have been calculated in cases with astigmatic refractive errors.

Binocular abnormalities. The ocular motility examination included determination of versions, near point of convergence, and cover/uncover tests at near and distance fixation. When needed the patients were also examined with the Maddox cross at $5 \mathrm{~m}$ and the Maddox wing test for near fixation.

Ocular deviations were determined with a prism cover test when the patient was wearing appropriate correction of refractive errors. Strabismus was defined as manifest or intermit-

Table 1 Premature population. Distribution according to birth weight (grams)

\begin{tabular}{lcccc}
\hline & $<1000$ & $1000-1500$ & $1501-1999 \star$ & Total \\
\hline Number of births & 148 & 443 & 274 & 865 \\
Survivors & 48 & 311 & 242 & 601 \\
Rate of survival & $32 \cdot 4 \%$ & $70 \cdot 2 \%$ & $88 \cdot 3 \%$ & $69 \cdot 5 \%$ \\
Number moved away & 5 & 37 & 31 & 73 \\
Number available & 43 & 274 & 211 & 528 \\
Number of ophthalmic & 19 & 79 & 36 & 134 \\
patients & $44 \cdot 1 \%$ & $28 \cdot 8 \%$ & $17 \cdot 0 \%$ & $25 \cdot 4 \%$ \\
Rate of ophthalmic care & 4 & & &
\end{tabular}

$\star$ Only patients $<33$ weeks of gestational age. tent heterotropia. A manifest or intermittent deviation of less than 10 prism dioptres was classified as microtropia.

Ophthalmoscopic examination. Information on ROP was obtained in the following manner. The records of the 134 preterm children were carefully screened. Five patients had undergone an examination under anaesthesia by experienced ophthalmologists, and the information contained in the records was considered to be sufficient for our study. Most other patients had not been examined by indirect binocular ophthalmoscopy, and peripheral changes might have been missed. We decided to perform a fresh eye fundus examination in these patients. In spite of large efforts 27 patients did not come for the examination, while 102 complied. Mydriatic drops were used to obtain a clear view of the retinal periphery. The fundus was examined with the indirect binocular ophthalmoscope and a 20 dioptre lens. The scleral depressor could not be used in any of these children aged 5-10 years. In two of the 102 patients the retinal periphery was impossible to examine clearly owing to manifest nystagmus in one patient and severe miosis in the other, who was treated with pilocarpine for congenital glaucoma. Thus exact information on fundus conditions was available for 105 of the 134 patients (see also Table 2).

In our classification of regressed ROP we have followed the suggestions of the International Committee for the Classification of late stages of ROP. ${ }^{14}$ The committee has pointed out that regressed ROP has a broad spectrum of eye fundus abnormalities, so wide that it does not allow investigators to classify them in different stages. However, to bring about some order in the various ophthalmoscopic findings the committee has suggested recording them topographically into peripheral and posterior changes, and then a subdivision can be made into vascular and vitreoretinal changes. In our study we have also included a subdivision into severe and moderate regressed ROP in order to differentiate the degree of severity. The severe form included cases with vitreoretinal scarring equal to or larger than one optic disc diameter and the presence of tangential (transgel) traction of the retina. The remaining cases (with only pigmentary changes and/or vitreoretinal interphase changes) constituted the group of patients with moderate regressed $R O P$.

\section{Results}

Table 1 shows the composition of the population of premature infants with respect to birth weight and other characteristics. Referrals for ophthalmic examination were commonest in the children with the lowest birth weights $(<1000 \mathrm{~g})$. The mean number of examinations in the group of patients was 8.7 times (SD 7.9 , range $1-62$ ), including those examinations made before the age of 5 years in children with severe ROP. One hundred and thirteen children $(84.3 \%)$ had been seen three or more times by ophthalmologists or orthoptists.

Myopia was found in 33 children (24.6\% of the children under ophthalmic care), unilateral in 14 and bilateral in 19 cases. Results of testing for 
Table 2 Regressed ROP and its relation with ocular abnormalities, immaturity, and birth weight

\begin{tabular}{|c|c|c|c|c|c|c|}
\hline & $\begin{array}{l}\text { SSROP } \\
(n=13)\end{array}$ & $\underset{(n=48)}{M R R O P}$ & $\begin{array}{l}S+M R R O P \\
(n=61)\end{array}$ & $\begin{array}{l}\text { WRROP } \\
(n=44)\end{array}$ & $\begin{array}{l}\text { IF-Inform } \\
(n=29)\end{array}$ & $\begin{array}{l}\text { Total } \\
(n=134)\end{array}$ \\
\hline \multicolumn{7}{|l|}{ Ocular motor disorders } \\
\hline $\begin{array}{l}\text { Strabismus } \\
\text { Nystagmus }\end{array}$ & $\begin{array}{l}7(53 \cdot 8 \%) \\
5(38 \cdot 4 \%)\end{array}$ & $\begin{array}{r}17(35 \cdot 4 \%) \\
3(6 \cdot 2 \%)\end{array}$ & $\begin{array}{r}24(39 \cdot 3 \%) \\
8(13 \cdot 1 \%)\end{array}$ & $\begin{array}{r}19(43 \cdot 2 \%) \\
1(2 \cdot 3 \%)\end{array}$ & $\begin{array}{l}9(31 \cdot 0 \%) \\
4(13 \cdot 8 \%)\end{array}$ & $\begin{array}{l}52(38 \cdot 8 \%) \\
13(9 \cdot 7 \%)\end{array}$ \\
\hline \multicolumn{7}{|l|}{ Refractive errors } \\
\hline $\begin{array}{l}\text { Myopia } \\
\text { Myopia >3 D } \\
\text { Anisometropia ₹1 D }\end{array}$ & $\begin{array}{l}8(61 \cdot 5 \%) \\
7(53 \cdot 8 \%) \\
8(61 \cdot 5 \%)\end{array}$ & $\begin{array}{r}14(29 \cdot 1 \%) \\
2(4 \cdot 2 \%) \\
10(20 \cdot 8 \%)\end{array}$ & $\begin{array}{r}22(36 \cdot 1 \%) \\
9(14 \cdot 7 \%) \\
18(29 \cdot 5 \%)\end{array}$ & $\begin{array}{l}5(11 \cdot 4 \%) \\
1(2 \cdot 3 \%) \\
8(18 \cdot 2 \%)\end{array}$ & $\begin{array}{l}6(20 \cdot 7 \%) \\
2(6 \cdot 9 \%) \\
5(17 \cdot 2 \%)\end{array}$ & $\begin{array}{l}33(24 \cdot 6 \%) \\
12(8 \cdot 9 \%) \\
31(23 \cdot 1 \%)\end{array}$ \\
\hline \multicolumn{7}{|l|}{ Visual acuity } \\
\hline $\begin{array}{l}\leqslant 0.6(6 / 9) \text { WE } \\
\leqslant 0.6(6 / 9) \mathrm{BE} \\
\leqslant 0.3(6 / 18) \text { WE } \\
\leqslant 0.3(6 / 18) \mathrm{BE} \\
\text { Blind }\end{array}$ & $\begin{array}{l}9(69 \cdot 2 \%) \\
6(46 \cdot 1 \%) \\
6(46 \cdot 1 \%) \\
3(23 \cdot 1 \%) \\
2(15 \cdot 4 \%)\end{array}$ & $\begin{array}{l}6(12 \cdot 5 \%) \\
3(6 \cdot 2 \%) \\
1 \quad(2 \cdot 1 \%) \\
- \\
-\end{array}$ & $\begin{array}{r}15(24 \cdot 6 \%) \\
9(14 \cdot 7 \%) \\
7(11 \cdot 5 \%) \\
3(4 \cdot 9 \%) \\
2(3 \cdot 3 \%)\end{array}$ & $\begin{array}{l}6(13 \cdot 6 \%) \\
3(6 \cdot 8 \%) \\
- \\
- \\
-\end{array}$ & $\begin{array}{r}10(34 \cdot 5 \%) \\
7(24 \cdot 1 \%) \\
3(10 \cdot 3 \%) \\
1(3 \cdot 4 \%) \\
-\quad(3)\end{array}$ & $\begin{array}{r}38(28 \cdot 3 \%) \\
19(14 \cdot 2 \%) \\
10(7 \cdot 5 \%) \\
4(3 \cdot 0 \%) \\
2(1 \cdot 5 \%)\end{array}$ \\
\hline \multicolumn{7}{|l|}{ Birth weight } \\
\hline $\begin{array}{l}<1000 \mathrm{~g} \\
1000-1500 \mathrm{~g} \\
1501-1999 \mathrm{~g}\end{array}$ & $\begin{array}{l}5(38 \cdot 5 \%) \\
7(53 \cdot 8 \%) \\
1(7 \cdot 7 \%)\end{array}$ & $\begin{array}{r}8(16 \cdot 7 \%) \\
29(60 \cdot 4 \%) \\
11(22 \cdot 9 \%)\end{array}$ & $\begin{array}{l}13(21 \cdot 3 \%) \\
36(59 \cdot 0 \%) \\
12(19 \cdot 7 \%)\end{array}$ & $\begin{array}{r}4(9 \cdot 1 \%) \\
24(54 \cdot 5 \%) \\
16(36 \cdot 4 \%)\end{array}$ & $\begin{array}{r}2(6 \cdot 9 \%) \\
19(65 \cdot 5 \%) \\
8(27 \cdot 6 \%)\end{array}$ & $\begin{array}{l}19(14 \cdot 2 \%) \\
79(58 \cdot 9 \%) \\
36(26 \cdot 9 \%)\end{array}$ \\
\hline \multicolumn{7}{|l|}{ Gestational age } \\
\hline $\begin{array}{l}26-29 \text { weeks } \\
30-32 \text { weeks } \\
33-37 \text { weeks }\end{array}$ & $\begin{array}{l}9(69 \cdot 2 \%) \\
4(30 \cdot 8 \%) \\
-\end{array}$ & $\begin{array}{l}17(35 \cdot 4 \%) \\
21(43 \cdot 7 \%) \\
10(20 \cdot 9 \%)\end{array}$ & $\begin{array}{l}26(42 \cdot 6 \%) \\
25(41 \cdot 0 \%) \\
10(16 \cdot 4 \%)\end{array}$ & $\begin{array}{r}11(25 \cdot 0 \%) \\
28(63 \cdot 6 \%) \\
5(11 \cdot 4 \%)\end{array}$ & $\begin{array}{r}5(17 \cdot 2 \%) \\
19(65 \cdot 6 \%) \\
5(17 \cdot 2 \%)\end{array}$ & $\begin{array}{l}42(31 \cdot 3 \%) \\
72(53 \cdot 8 \%) \\
20(14 \cdot 9 \%)\end{array}$ \\
\hline
\end{tabular}

Abbreviations: severe regressed ROP (SRROP); moderate regressed ROP (MRROP); without regressed ROP (WRROP); better eye (BE); worse eye (WE); incomplete fundus information (IF-Inform).

anisometropia and visual acuity are shown in Table 2.

Strabismus was found in 52 prematures $(38.8 \%)$, and of them esotropia was seen in 24 , exotropia in 13, and microtropia in 15 . A group of 13 prematures $(9 \cdot 7 \%)$ had nystagmus of different types: six horizontal, two end-point, and five latent nystagmus, respectively.

\section{REGRESSED ROP}

A total of 61 patients (45.5\%) presented signs of regressed ROP. Severe forms of regressed ROP was seen in 13 patients $(9.7 \%)$ and moderate forms in 48 patients $(35 \cdot 8 \%)$.

Regressed ROP occurred most commonly in children with a low birth weight and a low gestational age. It was seen in 13 out of 19 patients with a birth weight below $1000 \mathrm{~g}$ $(68.5 \%)$ and in 36 out of 79 patients between $1000-1500 \mathrm{~g}(45 \cdot 6 \%)$. Regarding gestational age, 26 out of 42 children $<30$ weeks $(61.9 \%)$ and 25 out of 72 children between 30-32 weeks (34.7\%) had signs of ROP.

Vitreoretinal scarring was larger than 3 optic disc diameters in all patients but one. Dragging of retina over the disc was found in five patients. A tractional retinal detachment was seen in three patients, while distortion of macula was diagnosed in four patients. Further information on posterior vitreoretinal changes is given in Table 3.

Table 4 highlights the peripheral vitreoretinal findings. Pigmentary changes were seen in $\mathbf{5 0}$ children, vitreous membranes in four, and lattice-like degeneration in one child.

REGRESSED ROP AND ITS RELATION WITH OCULAR ABNORMALITIES

Two patients $(1 \cdot 5 \%)$ were blind from ROP. Three patients with regressed ROP $(2 \cdot 2 \%)$ presented a visual acuity $\leqslant 0.3(6 / 18)$ in the better eye, while seven patients $(5 \cdot 2 \%)$ had a visual acuity $\leqslant 0.3(6 / 18)$ in the worse eye (Table 2$)$. The majority of these patients had the severe type of ROP, and only one of them showed the moderate form.
The relation between regressed $R O P$ and refractive errors can be seen in Table 2. Among 33 myopic patients and 31 anisometropic patients signs of regressed ROP were seen in $22(66.7 \%)$ and 18 patients $(58 \cdot 1 \%)$, respectively.

Fifty-two patients with strabismus and 13 with nystagmus constituted the group of children with ocular motility disorders. Regressed ROP was found in 24 patients with strabismus (46.1\%) and in eight patients with nystagmus $(61 \cdot 5 \%)$.

\section{SEVERITY OF REGRESSED ROP}

The severe form of regressed ROP was diagnosed in $26.3 \%$ of prematures with a birth weight less than $1000 \mathrm{~g}$, in $8.9 \%$ of those between 1000 $1500 \mathrm{~g}$, and in $2.8 \%$ of prematurely born children

Table 3 Ophthalmoscopic findings: posterior ROP changes

\begin{tabular}{llllll}
\hline & $\begin{array}{l}\text { Right } \\
\text { eye }\end{array}$ & $\begin{array}{l}\text { Left } \\
\text { eye }\end{array}$ & $\begin{array}{l}\text { No of } \\
\text { eyes }\end{array}$ & $\begin{array}{l}\text { No of } \\
\text { patients }\end{array}$ & $\begin{array}{l}\text { Rate } \\
(n=134)\end{array}$ \\
\hline $\begin{array}{l}\text { Vitreous } \\
\text { haemorrhage }\end{array}$ & 1 & - & 1 & 1 & $0 \cdot 74 \%$ \\
$\begin{array}{c}\text { Straightening of } \\
\text { vessels }\end{array}$ & - & 2 & 2 & 2 & $1 \cdot 5 \%$ \\
$\begin{array}{c}\text { Pigmentary } \\
\text { changes }\end{array}$ & 1 & 1 & 2 & 1 & $0 \cdot 74 \%$ \\
$\begin{array}{c}\text { Distortion/ectopia } \\
\text { of macula }\end{array}$ & 3 & 4 & 7 & 4 & $3 \%$ \\
$\begin{array}{c}\text { Vitreous } \\
\text { membranes }\end{array}$ & 1 & - & 1 & 1 & $0 \cdot 74 \%$ \\
$\begin{array}{c}\text { Dragging of retina } \\
\text { over disc }\end{array}$ & 3 & 4 & 7 & 5 & $3 \cdot 7 \%$ \\
$\begin{array}{c}\text { Tractional retinal } \\
\text { detachment }\end{array}$ & 3 & 3 & 6 & 3 & $2 \cdot 2 \%$ \\
\hline
\end{tabular}

Table 4 Ophthalmoscopic findings: peripheral ROP changes

\begin{tabular}{lcccccc}
\hline & $\begin{array}{l}\text { Right } \\
\text { eye }\end{array}$ & $\begin{array}{l}\text { Left } \\
\text { eye }\end{array}$ & $\begin{array}{l}\text { No of } \\
\text { eyes }\end{array}$ & $\begin{array}{l}\text { No of } \\
\text { patients }\end{array}$ & $\begin{array}{l}\text { Rate } \\
(n=134)\end{array}$ \\
\hline $\begin{array}{l}\text { Pigmentary } \\
\text { changes }\end{array}$ & 34 & 40 & 74 & 50 & $37 \cdot 3 \%$ \\
$\begin{array}{l}\text { Vitreoretinal } \\
\text { interface changes }\end{array}$ & 1 & 4 & 5 & 4 & $3.0 \%$ \\
$\begin{array}{l}\text { Vitreous } \\
\text { membranes }\end{array}$ & 2 & 3 & 5 & 4 & $3 \cdot 0 \%$ \\
$\begin{array}{c}\text { Lattice-like } \\
\text { degeneration }\end{array}$ & 1 & - & 1 & 1 & $0 \cdot 74 \%$ \\
$\begin{array}{c}\text { Tractional retinal } \\
\text { detachment (only } \\
\text { in periphery) }\end{array}$ & - & 1 & 1 & 1 & $0 \cdot 74 \%$ \\
\hline
\end{tabular}


in the 1501-1999 $\mathrm{g}$ bracket (see Table 2). The same degree of severity was found in $21 \cdot 4 \%$ of children with a gestational age $<30$ weeks, in $5 \cdot 5 \%$ of those between $30-32$ weeks, and in none of the patients with a gestational age $>32$ weeks.

Among 13 patients affected with severe regressed ROP eight had anisometropia $\geqslant 1 \mathrm{D}$, eight had myopia, and of these patients seven had myopia of more than $3 \mathrm{D}$. These were higher values than in patients with moderate regressed ROP or in those without regressed ROP (Table 2).

\section{OCULAR ABNORMALITIES IN PATIENTS WITH} INCOMPLETE FUNDUS EXAMINATION

Only one of the 29 patients with incomplete fundus examination had poor vision - that is, visual acuity below or equal to $0.3(6 / 18)$ in the better eye - but three of them had a visual acuity $\leqslant 0.3(6 / 18)$ in the worse eye, and 10 patients had a visual acuity level $\leqslant 0.6(6 / 9)$ in the better eye. Six of the children not examined were myopic, while five had anisometropia $\geqslant 1 \mathrm{D}$. With regard to ocular motility disorders, strabismus and nystagmus were present in nine and four patients, respectively (Table 2 ).

\section{Discussion}

This report on the occurrence and characteristics of regressed ROP in prematurely born children is part of a retrospective study of the ocular changes in 528 prematures born in Stockholm county during the years $1976-81$.

Although our study suffers from the lack of information on acute ROP, we believe this is not an impediment to analysing the fundus findings of premature children aged 5-10 years. However, it may be reasonable to suggest that some of the so-called signs of regressed ROP in our study could have been the result of conditions other than prematurity. None the less, this is hardly the case in our population of patients. First of all, none of the children with signs of regressed ROP had a history of a disease which can simulate ROP changes in its regressed form, such as familial exudative retinopathy, persistent hyperplastic vitreous, incontinentia pigmenti, $\mathrm{X}$-linked retinoschisis, retinal dysplasia, toxoplasmosis, and cytomegalic inclusion disease. ${ }^{15}$ Moreover, most of the children in our study had a long follow-up, and no information on other ocular pathology and systemic diseases with possible fundus changes was found in the records than what is reported here. We believe that the risk of having misdiagnosed some of the fundus findings is very low.

Most of the findings on regressed ROP were obtained at a re-examination of the children during 1987-8, when they were 6-11 years old. Based on these findings the incidence was $45 \cdot 5 \%$. However, among the 134 children who had been referred to ophthalmologists for different reasons and who constitute our study group, 27 (20\%) did not come for the re-examination. Available data showed that the drop-outs represented $25 \%$ of the children with VA $\leqslant 0.3(6 / 18), 37 \%$ of those with VA $\leqslant 0 \cdot 6(6 / 9)$ in the better eye, $18 \%$ of the myopic children, $16 \%$ of the patients with anisometropia, $30 \%$ of the patients with nystagmus, and $17 \%$ of those with strabismus. Since there is a connection between such findings and ROP, it is very likely that the number of patients with regressed ROP would have been higher if it had been possible to examine all the patients properly. Therefore the true incidence of regressed ROP in premature children born in Stockholm and who needed ophthlamic care for different reasons can be expected to fall within the range $45 \cdot 5 \%-65 \cdot 6 \%$.

It is well established that ROP is commoner in premature babies of low birth weight than others. In our material regressed ROP was seen in about two-thirds of the prematures with birth weights $<1000 \mathrm{~g}$. Similar findings were seen with regard to immaturity. More than half the children with gestational age $<30$ weeks had ROP.

The most severe forms of regressed ROP were seen in two blind children. Severe regressed ROP was connected with reduced visual acuity $\leqslant 0 \cdot 3$ $(6 / 18)$ in the better eye - that is, with visual handicap. Children with moderate regressed ROP or with no signs of regressed ROP never showed reduced vision to this level.

The role of ROP in the development of ocular abnormalities is well established. ${ }^{2-5}{ }^{16}$ In our study a close association could be observed between regressed ROP and myopia, particularly between the severe forms of regressed ROP and high myopia, which is in accordance with previous reports. ${ }^{4118}$ The frequency of anisometropia was higher in children with regressed ROP than in those who did not present signs of this disease. Strabismus was slightly commoner in cases with regressed ROP, and patients with nystagmus suffered more often than not from sequelae of ROP. Refractive errors are likely to represent developmental changes in the eye, probably induced by the same processes as those underlying regressed ROP. Strabismus and nystagmus, on the other hand, probably reflect developmental changes in the central nervous mechanisms of binocular vision and oculomotor control, and would therefore not be correlated with the severity of regressed ROP.

With regard to the ophthalmoscopic findings, pigmentary changes were the commonest signs of regressed ROP. Although the evaluation might be subjective, it is interesting to note that a broad spectrum of pigmentary changes can be found. According to the observations of Foos, ${ }^{19}$ focal pigmentations correspond microscopically to scattered pigmentation of the retina, as a consequence of the intraretinal proliferation at the time of injury. Pigmentary lines might also be the result of intraretinal proliferations or the ophthalmoscopic appearance of retroretinal membranes. These membranes have been reported in advanced cases of ROP. ${ }^{20}$ In our patients we could not see any retroretinal membrane in cases without retinal detachment.

Vitreous membranes were observed in six eyes of four patients with regressed ROP in our study. These membranes may be glial in origin, but, as Foos has pointed out, ${ }^{20}$ they can be seen in cases of arrested ROP in which the extraretinal vascular component has been involuted. The clinical significance of these membranes in arrested ROP 
is not well understood. It should be noted that all these patients except one had visual acuity of 0.5 $(6 / 12)$ or better in the worse eye, which means that central retinal function was not markedly affected. One patient had normal ocular motility, but the others had strabismus and/or nystagmus. Unfortunately we have no information on the retinal conditions of these children during the neonatal period and early infancy, and we cannot evaluate the possible morphological changes of these membranes during the time preceding our examination.

The high frequency of regressed ROP in our material strongly indicates that prematurely born children are an ophthalmological risk group, with increased incidence of refractive errors, strabismus, and retinal complications. They must therefore be carefully followed up during the period of visual development in order to prevent visual dysfunction by intervention as early as possible.

Finally, paediatricians and ophthalmologists must continue jointly to investigate the conditions that predispose to ROP in the hope of preventing or at least diminishing the severity of the disease. For this purpose a study of risk factors in ROP has been performed.

Part of the results of this paper were presented at the 18th European Strabismological Association meeting in Krakow, Poland, on 21-22 October 1989.

This work was supported in part by the Swedish Medical This work was supported in part by the Swedish Medical
Research Council (grant no 4751), Limmat-Stiftung, KMA for synskadade, Stiftelsen Samariten and Stiftelsen Sven Jerrings ond.

We are grateful to Mr Anders Eriksson, of the Swedish National Board of Health and Welfare, for obtaining data from the birth registers and for valuable advice. We also thank Dr Enrique Malbran for constructive discussions and members of staff at the departments of neonatology, paediatrics, and ophthalmology in
Stockholm for all the assistance they have given in the collection of information on the children under study.

1 Phelps D. Retinopathy of prematurity: An estimate of vision loss in the United States - 1979. Pediatrics 1981; 67: 924-6. 2 Gordon R, Donzis P. Myopia associated with retinopathy of prematurity. Ophthalmology 1986; 93: 1593-8.

3 Kushner B. Strabismus and amblyopia associated with regressed retinopathy of prematurity. Arch Ophthalmol 1982; 100: 256-61.

4 Nissenkorn I, Yassur Y, Mashkowski D, Sherf I, Ben-Sira I. Myopia in premature babies with and without retinopathy of prematurity. Brf Ophthalmol 1983; 67: 170-3.

5 Tasman. Late complications of retrolental fibroplasia. Ophthalmology 1979; 86: 1724-40.

6 Flynn J, Bancalari E, Bawol R, et al. Retinopathy of prematurity: a randomized, prospective trial of transcutaneous oxygen monitoring. Ophthalmology 1987; 94: 630-8.

7 Prendiville A, Schulenburg W. Clinical factors associated with retinopathy of prematurity: Arch Dis Child 1988; 63: 522-7.

8 Cryotherapy for Retinopathy of Prematurity Cooperative Group. Multicenter trial of cryotherapy for retinopathy of prematurity. Arch Ophthalmol 1988; 106: 471-9.

9 Lennerstrand G, Gallo JE. Prevalence of refractive errors and ocular motility disorders in 5-10 years old Swedish children born prematurely or at full-term. 1989. Acta Ophthalmol $(K b h)$ 1989; 67: 717-8.

10 Official statistics of Sweden, National Board of Health and Welfare. Stockholm: 1981. .

11 Köhler L, Stigmar G. Vision screening of four-year-old children. Acta Paediatr Scand 1973; 62: 17-27.

12 Köhler L, Stigmar G. Visual disorders in 7-year-old children with and without previous vision screening. Acta Paediat Scand 1978; 67: 373-7.

13 Dubowitz L, Dubowitz V, Goldberg C. Clinical assessment of gestational age in the newborn infant. $\mathcal{F}$ Pediatr 1970;77: 1

14 Committee for the classification of the late stages of retinopathy of prematurity. An International Classification of retinopathy of prematurity. Arch Ophthalmol 1987; 105: 906-12.

15 Tasman W. Diseases of the retina and vitreous. In: Robinson Harley, ed. Pediatric Ophthalmology. Philadelphia: Saunders, 1975; 347-69.

16 Schaffer D, Quinn G, Johnson L. Sequelae of arrested mild retinopathy of prematurity. Arch Ophthalmol 1984; 102: retinop.

17 Fletcher MC, Brandon S. Myopia of prematurity. $A m \mathcal{F}$ Ophthlamol 1955; 40: 474-81.

18 Keith CG, Kitchen WH. Ocular morbidity in infants of very low birthweight. Brf Ophthalmol 1983; 67: 302-5.

19 Foos R. Retinopathy of prematurity. Pathologic correlation of clinical stages. Retina 1987; 7: 260-76.

20 Foos R. Chronic retinopathy of prematurity. Ophthalmology 1985; 92: 563-74. 